\title{
Erratum to: Physics in Novosibirsk and Akademgorodok
}

Natalia Kupershtokh and Alexander Apolonskiy

\section{Erratum to: Phys. Perspect. 16 (2014) 250-276 DOI 10.1007/s00016-014-0138-4}

In the original version of this article some names were unfortunately misspelled. In the second paragraph of Sect. "Novosibirsk's Science Center: Akademgorodok", the second sentence should read:

The idea of a research center based on an academic model to be located in Siberia was proposed by academicians Mikhail Lavrentyev, Sergei Sobolev, and Sergei Khristianovich (figure 6).

The end of the seventh paragraph of Sect. "A Tour of Akademgorodok" after Fig. 10, should read:

The second and current director of the institute is Alexander Skrinsky.

The caption of Figure 12 should read:

Fig. 12. Five key individuals of the Budker Institute of Nuclear Physics, from left to right: Gersh Budker (its first director), Alexander Skrinsky (the second and current director), Dmitri Ryutov, Lev Barkov, Gennadi Kulipanov. Source: http:// www.ras.ru.

On page 19 the beginning of the last paragraph should read:

In 1958, the Central Siberian Geological Museum was founded at the Institute of Geology and Geophysics.

On page 24 the first sentence of the second paragraph should read:

The left turn in the middle of Morskoi Avenue, Zolotodolinskaya Street, leads to the Botanical Garden of the Siberian Branch of the Russian Academy of Sciences

The online version of the original article can be found under doi:10.1007/s00016-014-0138-4. 
(approximately $20 \mathrm{~min}$ on foot), and to Lavrentyev's house (Zolotodolinskaia, 75). Today, this is the museum of the Siberian Branch of the Russian Academy of Sciences.

Department of Physics

Ludwig Maximilian University of Munich

Am Coulombwall 1

85748 Garching, Germany

e-mail: apolonskiy@lmu.de 